\title{
The Role of Readability in Science Education in Ghana: A Readability Index Analysis of Ghana Association of Science Teachers Textbooks for Senior High School
}

\author{
William Kodom Gyasi \\ Department of Communication studies University of Cape Coast, Ghana
}

\begin{abstract}
The study investigated the readability of science textbooks for senior high schools in Ghana. Survey research design was employed for the study. Using stratified sampling technique, a sample size of 300 SHS 1, 2 and 3 students were drawn from five senior high schools in the Cape Coast Metropolis, Ghana. Gunning Fog and Cloze Test readability indexes were used to examine the difficulty level of the Physics, Chemistry, Biology and Integrated Science textbooks for senior high schools, written by the Ghana Association of Science Teachers. Findings of the study revealed that, on the average, the books are difficult to read. The study further showed that the Integrated Science textbook is the most difficult among the textbooks, followed by the Physics textbook. The study concludes by proffering the following recommendations: long sentences and multi-syllable words in these books should be reformulated into smaller structures for easy understanding; and the Ghana association of Science Teachers should write more simplified text materials that can improve readership and understanding. Keywords: text readability; readability index, Gunning Fog Scale; Cloze Test Index of Readability; Ghana Association of Science Teachers; approved science textbooks for senior high schools in Ghana.
\end{abstract}

Submitted Date 05 June 2013

Accepted Date: 10 June 2013

\section{Introduction}

In his speech during a convocation address at Allahabad University in 1946, Nehru said, it is science alone that can solve the problems of hunger and poverty, of insanitation and malnutrition, of illiteracy and obscurantism, of superstition and deadening customs, of rigid traditions and blind beliefs, of vast resources going to waste, of a rich country inhabited by starving millions (cited in Gaillard, 1991). In the context of establishing modern science and technology as a live and vital force to alleviate the multifaceted problems facing our dear nation, the significance of science education cannot be over-stretched. Indeed, science education plays a crucial and pivotal role in the alchemy of scientific research and technological innovations in any given country.

However, science education without readable and appropriate textbooks is comparable to democracy without appropriate constitution or farming without functional farm implements. Farmer et al. (2007:206) affirm that "textbooks constitute the most fundamental source of reference for students." They further state that textbooks are

printed educational and instructional materials comprised of rich texts equipped with cognitive and perceptive capabilities appropriate for age and knowledge levels of students, prepared on the basis of principles on which education programs are grounded, and transferring the contained knowledge to students.

Corroborating this point, Unsal and Gunes (2008:388) posit: "these books are at the same time the most important tools enabling the individual to work independently and repeat the information for many times".

In view of the important void science textbooks fill, its readability should be of serious concern to both writers and tutors, because, according to Wellington and Osborne (2001), language use is the major barrier to most students in learning science. With the dominance of the English language in the linguistic ecology of Ghana, it has come to stay as the official language of the country and is used as the main medium of instruction in schools. This medium of instruction and its influence on learning science in our schools, according to Yong (2010), has become an important issue. Studies have found that students encounter numerous problems because learning science through English is complicated by having to simultaneously master both the science content and language at the same time (Rollnick, 1999). Lemke (1997) reported that students in English as a second language situations have to immerse in two social practices together at the same time when learning science: one which has to do with learning a new language (i.e. English) and the other which has to do with learning science (i.e. language of science).

Several researchers have indicated that the language used in some science textbooks exceeds the normal experience of many high school students (Lynch, et al., 1972 cited in Letsoalo, 1996, p. 184) for whom 
they are written. Curtis and Millar (1988) contended that if the understanding of textbook language is difficult for English speakers, it is likely to be even more difficult for students who learn science in a second language. In the local context, it has long been recognized that students encounter enormous problems learning science in a second language (Heppner et al., 1997; Yong, 2003, Mohiddin, 2007; Romaizah, 2009 ;). Many senior high school teachers believe that students' performance in science would be very much improved if serious attention is given to the readability of the approved science textbooks used in the schools. They argue that it is the language used and style of writing that is the main stumbling block for learning science rather than the science content itself.

Underscoring the seriousness of the role readability plays in education, Scott (2011) writes that "written text in the form of textbooks forms the backbone of a good education system. A "good" text forms the basis of a good learning experience for students. Scott explained that the quality of a "good" text include its readability. The text should be easy enough to comprehend and difficult enough to contribute to students' academic development.

In harmony with the above expressions, the preface of the science textbooks written by the Ghana Association of Science Teachers (GAST) state: "the language level and depth in the text reflect the year group for which the text is written. This facilitates easy reading and understanding" (Physics Textbook written by GAST, 2002). They further state that "the text is well and attractively illustrated with photographs and large, simple, clear and well-labeled diagrams to aid quick understanding and arouse interest."

Several educationists have lauded the contribution of the science textbooks towards science education. The Ghana Education Service has consistently conducted deliberate interventions geared towards encouraging the study of science. For example, Science clinics were introduced for girls during the long vacations to help promote girls' interest in Science and by so doing get more girls to take to the sciences as they get to senior high school. A number of corporate institutions were encouraged by the initiative and gave it their support.

In echoing other sources encouraging science education, Wireko (2009) intimates that the private sector has done a lot to promote children's interest in the subject. For example, Primetime Ltd, a local advertising company, introduced the Brilliant Math and Science Quiz some fifteen years ago which hooked several individuals and children alike to science as a subject. This initiative thus sustained the learning interest.

Also, a decade ago, the Unilever Ghana Foundation for Education and Development instituted an annual nationwide Young Scientists Award for children below the age of sixteen to encourage innovation and scientific thinking. All these activities made science and mathematics interesting for all, particularly, students.

In spite of all these encouragement and assistance towards heightened interest in science education, a report given by a team of educational scientists from the University of Cape Coast and the University College of Education, Winneba, in 2009 indicated that Ghana's performance in the sciences is simply pathetic. The team was tasked to assess the performance and impact of 48 nations in the international Maths and Science competition. Ghana was ranked 47th and last in the Mathematics competition and 48th and also last in Science. In fact, among African countries, Ghana was still the weakest among the six African countries that participated in the quiz programme. Botswana placed 43rd and 46th in Maths and Science respectively. Egypt was in the 38th and 41st positions in Maths and Science respectively.

This poor performance shows that something serious is amiss; this aroused an urgent inquiry among several educators and researchers (Wireko, 2009).

A brief survey I conducted among teachers and students reveals that there is low readership of the approved science textbooks written by the Ghana Association of Science Teachers for senior high schools. While some of the factors responsible for this situation could be socially or psychologically inclined, it would be important to explore the readability of these textbooks to ascertain whether they match the grade level of targeted readers.

The aim of the present study is to subject the four science textbooks - Physics, Chemistry, Biology and Integrated Science written by the Ghana Association of Science Teachers to a readability test, using two readability indexes, namely, Gunning Fog Scale and Cloze Test Readability Index.

Subjecting these textbooks to a readability index analysis is important because readability indexes are a prerequisite to improving students' proficiency in the English language. It can also be an indicator and guide to ascertain students' comprehension of texts in a book. Illuminating their importance, Scott (2011) state that 'Right from their inception in the late 1940s, readability indexes revolutionized the writing style of everyone...they affect every industry because of their all-appealing premise."

Among other things, readability formulas help assess and develop textbooks and other written material for the exact grade level. For instance, if an author prepares textbooks for third grade level students and the appropriate readability formula tells the author the textbooks are for the fifth grade level, it helps the author to revise the text. A readable text produces greater comprehension, retention, reading speed, and motivates readers. 


\section{Methodology}

Two readability indexes were used for the study - Gunning Fog and Cloze Text Readability Indexes. The readability of the textbooks was first determined by using Gunning Fog Readability Index. Gunning's Fog

Index is one of the best known readability indexes and measures the level of reading difficulty of any document (Ivan, 2010). The underlying principle of the Gunning Fog Index formula is that short sentences written in plain English achieve a better score than long sentences written in complicated language (Miles 1990).

The researcher also used the cloze test to assess the reading ability of the students. The technique involves the ability of students to select appropriate words if occasional gaps occur in a passage based on their abilities to infer meaning from context (Taylor, 1956). As Todd (2008) notes, "Cloze tests are relatively easy to administer and provide valid and reliable information about a student's language proficiency through deliberate deletion of targeted language features such as verb forms, prepositions and lexical items." Moreover, Ayodele (2012) employed it in a recent research in connection with basic science and technology textbooks for primary schools with impressive results. A passage was selected from each text book and every $4^{\text {th }}$ word was deleted from the passage. The students were asked to insert the appropriate words in a word bank provided at the bottom of the test for the 50 blank spaces in the passage.

After the completion of the test, the cloze passage was scored. Spelling errors were not penalized. The raw score was the number of words that are inserted correctly. The number of correct instances was doubled to find the percentage. That is, for 40 correct replacements, $40 \times 2=80 \%$. Below is a table that explains the various levels of difficulty of the cloze text procedure

Table R2: Students' Reading Level in Relation to Scores in the Cloze Test and Suitability of the Text Material

\begin{tabular}{|l|l|l|}
\hline Percentage & Type of Material & Level of difficulty \\
\hline $0-43 \%$ & Material is too difficult & Frustration Level \\
\hline $44-57 \%$ & Material is about right & Instructional Level \\
\hline $58-100 \%$ & Material is too easy & Independent Level \\
\hline
\end{tabular}

Source: Adapted from Bachman, 1985.

Independent level according to Table R2 occurs when a student's score is between $58-100 \%$, indicating students could effectively learn with the textbook with minimal teacher instruction. Instructional level refers to a situation where a student's score is between $44-57 \%$, this means student experience reasonable difficulty level, so that the textbook is adequate for learning with teacher instruction. Frustration level occurs when a student score is between $0-43 \%$, this means even with instruction the textbook will probably be too difficult for learning (Bachman 1985).

Using stratified sampling technique, a sample of 300 students was selected from five schools. The breakdown is presented below:

Table R1: Breakdown of respondents sampled

\begin{tabular}{|l|l|l|l|l|}
\hline School & SHS 1 & $\begin{array}{l}\text { SHS } \\
\mathbf{2}\end{array}$ & SHS 3 & Total \\
\hline Ghana National College & 20 & 20 & 20 & 60 \\
\hline Mfantisipim School & 20 & 20 & 20 & 60 \\
\hline Edinaman Senior High School & 20 & 20 & 20 & 60 \\
\hline St. Augustine College & 20 & 20 & 20 & 60 \\
\hline Adisadel College & 20 & 20 & 20 & 60 \\
\hline Grand Total: & 300
\end{tabular}

n=300 Sources: Field Survey Data, 2013.

As shown in Table R1, a total of 300 students from five senior high schools in Cape Coast were used for the study. The sample consisted of 100 SHS 1 students with an average age of 14.5 years, 100 SHS 2 students with an average age of 15.5 years, and 100 SHS 3 students with an average age of 16.5 years.

Passages used for the Fog analysis were selected from the beginning, middle and towards the end of the textbooks. The mean value of the score of three chosen passages in each textbook represented the average readability level of the textbook.

The selected passages from each of the science textbooks (Physics, Chemistry, Biology and Integrated Science) were fed into the computer and were subjected to readability test using the Gunning Fog readability index. 
Ivan (2010) indicates that the ideal score for readability with the Fog index is 7 or 8 . Anything above 12 is too hard for most people to read. Miles (1990) asserts that readability scores from 1-8 are might for elementary school students,9-12 for high school students and 13-16 for post high school students.

\section{Result and Findings}

This section presents the findings of the study. The first aspect of this section deals with the results of Gunning Fog Index analysis (Table R3) for all the textbooks and the second part discusses the result of the cloze test (Table R4).

Table R3: Result of Readability test

\begin{tabular}{|c|c|c|c|c|c|}
\hline \multirow{2}{*}{ Textbook } & \multicolumn{3}{|l|}{ Scores } & \multirow[b]{2}{*}{$\begin{array}{l}\text { Mean } \\
\text { Score }\end{array}$} & \multirow{2}{*}{ Remarks } \\
\hline & $\begin{array}{l}\text { Beginni } \\
\text { ng }\end{array}$ & $\begin{array}{l}\text { Midd } \\
\text { le }\end{array}$ & $\begin{array}{l}\text { Towards the } \\
\text { end }\end{array}$ & & \\
\hline Physics & 14.7 & 12.3 & 14.8 & 14 & Difficult to read \\
\hline Chemistry & 13.2 & 9.7 & 10 & 11 & $\begin{array}{l}\text { Fairly difficult to } \\
\text { read }\end{array}$ \\
\hline $\begin{array}{l}\text { Integrated } \\
\text { Science }\end{array}$ & 17.1 & 17.5 & 13.9 & 16 & Difficult to read \\
\hline Biology & 12.1 & 13.3 & 13.3 & 13 & Difficult to read \\
\hline
\end{tabular}

Source: Field Survey Data, 2013.

Table R3 above showed that though the textbooks contained a lot of useful information that can equip students scientifically, the readability index revealed that they are very difficult to read and understand. A quick comparison of the results as shown on Table R3 indicated that of all the textbooks, Integrated Science textbook is the most difficult text, scoring as high as 17.5 and on the average 16 which is far from 12 which is considered fairly readable for all type of audiences (Ivan 2010). Given the fact that fog index scores from 13-16 are might for post secondary readers, it can safely be concluded that the integrated science text book was written far above the reading comprehension level of the senior high school students in Ghana. For that reason, senior high school students would find it difficult to comprehend the test. (Miles 1990). The Physics textbook also had as high as 14.8, which means comprehension will be difficult for the students . This is because it also scored a Fog index that is might for post senior high school student (Miles 1990). The Chemistry textbook however scored a Fog index of 11 which is appropriate for senior high school students (Miles 1990). To Ivan (2010), however, Fog index of 11 is just manageable for most readers.

As depicted in Table R3, most of the textbooks are difficult to read. Gunning Fog readability index revealed that the textbooks were written above the students' reading level, especially in the case of Integrated Science textbook which scored 16 on the average which is might for post senior high school readers.

Table R4: Percentage of respondents who read the text materials at independent, instructional and frustration levels based on the scores obtained in the Cloze Test

\begin{tabular}{|l|l|l|l|l|}
\hline Textbooks & Cloze Reading Levels & Scores & Number of Students & Percentage \\
\hline Physics & Independent level & $60-100 \%$ & 43 & $14.3 \%$ \\
\hline & Instructional Level & $40-59 \%$ & 98 & $32.7 \%$ \\
\hline & Frustration Level & $0-39 \%$ & 159 & $53.0 \%$ \\
\hline & Total & & & $100.0 \%$ \\
\hline & Independent level & $60-100 \%$ & 86 & $28.7 \%$ \\
\hline & Instructional Level & $40-59 \%$ & 144 & $48.0 \%$ \\
\hline & Frustration Level & $0-39 \%$ & 70 & $23.3 \%$ \\
\hline Int. Science & Total & & & $100.0 \%$ \\
\hline & Independent level & $60-100 \%$ & 39 & $13.0 \%$ \\
\hline & Instructional Level & $40-59 \%$ & 66 & $22.0 \%$ \\
\hline Biology & Frustration Level & $0-39 \%$ & 195 & $65.0 \%$ \\
\hline & Total & & & $100 . \%$ \\
\hline & Independent level & $60-100 \%$ & 69 & $23.0 \%$ \\
\hline & Instructional Level & $40-59 \%$ & 98 & $32.7 \%$ \\
\hline & Frustration Level & $0-39 \%$ & 133 & $44.3 \%$ \\
\hline & Total & & & $100.0 \%$ \\
\hline
\end{tabular}

$$
\mathbf{n}=300
$$

Source: Field Survey Data, 2013.

Table R4 clearly revealed that the Physics, Integrated Science, Chemistry and Biology textbooks written for SHS 1, 2 and 3 were written above the reading and comprehension level of the intended readers The three classes of the Senior High Schools in Ghana.

Examination of Table R4 above shows that all the textbooks on the average are fairly difficult for students to understand as revealed in the percentage of students who experienced frustration in the course of 
reading the text materials. For example, 195 representing $65 \%$ of the respondents are reading the Integrated Science textbook at frustration level. Also, 159, representing 53\% of the respondents, are reading the Physics textbook at frustration level. However, the situation improved with Chemistry textbook because only 70 , representing $23.3 \%$ of the respondents, are reading it at frustration level.

Table R4, further showed that only $39(13 \%)$ of the respondents can read the Integrated Science textbook meant for Senior High Schools independently without assistance from teachers, while only $14.3 \%$ can read the Physics textbook at independent level. It is noteworthy that $28.7 \%$ of the respondents can read the Chemistry textbook at independent level, while 69 representing $23 \%$ can read the Biology textbook independently without assistance from teachers. The result as depicted on Table R4 indicated that majority of the respondents cannot read the textbooks independently; overall $46.4 \%$ of the respondents are reading the various textbooks at frustration level, $33.8 \%$ are reading it at instructional level, and only $19.8 \%$ can read the science textbooks at independent level.

Interested in unveiling the source of this unwelcomed failure, the researcher also conducted a brief interview with some seasoned science teachers coupled with a number of students.

After highlighting the valuable information contained in the approved biology textbook, Geshon Mensah, a biology teacher in Edinaman Senior High School, stated: "the students are not performing well academically because they are not reading the approved biology textbook which was prepared to assist them gain a good grasp of science, they preferred other science textbooks" Another biology teacher from Ghana National College, Doris Esseam, said "several students are not inclined to use the approved biology textbook, even though they have it, hence they are just tagging along in their studies" Corroborating the above expressions, Ama Amenakoma, a chemistry teacher in Ghana National College, stated "many students are comfortable using other chemistry textbooks and recoils at the mention of the approved chemistry textbook written by GAST" Kennedy Prempeh, a Physics teacher in Ghana National College also mentioned that it is becoming very difficult to teach students these days, they cannot fully understand discussions in the classroom because many do not come to class with their approved Physics textbook which could have facilitated understanding of basic principles in physics."

The researcher also conducted interview with a cross-section of the students, their comment are noteworthy. For example, an SHS1 student commented: "Integrated science textbook is too voluminous and difficult to understand". An SHS2 student also commented that he always calls on his teacher to explain several terms before he could fully understand the physics textbook. One of the girls in SHS2 said she was tired of checking meanings of words in a dictionary when reading the approved chemistry and physics textbooks, hence she dumped the book.

Findings of this interview corroborate the results of the study that the textbooks were written above the reading level of the students.

\section{Conclusion and Recommendation}

The major findings of the investigative study revealed that, apart from the Chemistry textbook for senior high school, which is fairly difficult according to Ivan (2010) but appropriate for senior high school students according to miles (1990), the others are above the reading comprehension levels of the students, to read and comprehend, all other textbooks - Physics, Integrated Science and Biology are very difficult to read and comprehend. In fact they were written quite above the students reading level. Table R3 and R4 vividly portray that the majority of the respondents $(46.4 \%)$ could not understand the textbooks even with instruction while a large section of the respondents (33.8\%) cannot understand the textbook even at the instructional level. This is due largely to the textbooks being written above their reading level, for example, Integrated Science textbook scored $17.5 \%$ (Table R3) on the Gunning Fog scale of readability indicating the textbook was far above the reading level of SHS 3 students. The findings of this study are similar to the result of a recent research conducted by Rubagumya et al. (2010) on Language of Instruction and Quality of Learning in Tanzania and Ghana. Their report indicated that in "both Ghana and Tanzania ...textbooks were difficult for learners to read. Language use in most textbooks was above the level learners can understand.” (p. 1).

Findings emanating from this study are a linchpin to identifying why students are reluctant to read the Ghana Association Of Science Teachers Science textbooks. In order to address this situation, it would be appropriate to use readability indexes to determine the readability of the various textbooks used at all grade levels (1-12) in the country. Efforts should be geared towards reducing long and complicated sentences so as to fan the flickering embers of the desire and interest of the Ghanaian senior high school students to read these valuable books. 


\section{References}

[1]. Ang, A. and Gill, B. (2003). Book review of the work of Ministry of Education Elementary 8. interms of physical science course workbook topics the class a critical look. Kastamonu Education Journal, 11 (2), 387-394.

[2]. Ayodele, M. O. (2012). Readability levels of basic science and technology textbooks for primaryschools. Research Journal in Organizational Psychology \& Educational Studies 1(1) (2012) 33-36

[3]. Burke, V., and Greenberg, D. (2010). Determining readability: How to select and apply easy-to-use readability formulas to assess the difficulty of adult literacy materials. Adult Basic Education and Literacy Journal, 4, 34-42.

[4]. Curtis, S. \& Millar, R. (1988). Language and conceptual understanding in science: a comparison of English and Asian speaking children. Research in Science and Technological Education, 6(1) 61-78.

[5]. Farmer, Ö., Chechen, M. A. and Melanlıŏlu, D. (2007). Sixth-grade English class in terms ofreadability of text books. The Social Science magazine. 6 (22), 206-219.

[6]. Gaillard, J. Scientists in the Third World. Lexington: University of Kentucky Press, 1991.

[7]. Heppner, F. H., Heppner, M. C. \& Leong, Y. P. (1997). Teachers' estimate of, andmeasurements of students' reading ability, and readability of text materials in English as a second language secondary Biology course. Journal of Applied Research in Education, $1(2), 31-39$.

[8]. Ivan, A. (2010). Klariti.com. Fog Index and Readability Formulas. Available athttp://www.klariti.com/business-writing/Fog-IndexReadability-Formulas.shtm1\#top.. Accessed on March 12, 2013.

[9]. Lemke, J. (1997). Cognition, context and learning: a social semiotic perspective. In Kirschner, D. \& Whitson, J. A. (Eds.), Situated cognition, semiotic and psychological perspectives, (pp. 37-56), Mahwah: Lawrence Erlbaum.

[10]. Letsoalo, M.B. (1996). Improving text for English second language biology pupils. Journal of Biological Education, $30(3), 184-186$.

[11]. Mohiddin bin Haji Noordin (2007). Students' achievement in biology in public and private schools: Understanding the differences. Unpublished Masters Project, Universiti Brunei Darussalam.

[12]. Miles, T., (1990). The fog index: a practical readability scale. West Virginia University. Retrieved April 2, 2006, from http://www.as.wvu.edu/ tmiles/fog.html

[13]. Rollnick, M. (1999). The influence of language on second language teaching and learning science. In Clements, M.A. (Ken) \& Leong, Y.P. (Eds.), Cultural and language aspects of science, mathematics and technical education,(pp. 123-132). Gadong: Universiti Brunei Darussalam.

[14]. Romaizah Salleh. (2009). Brunei primary pupils' ideas of water cycle: effects of culture and language. Jurnal Pendidikan, 14, 70-80.

[15]. Rubagumya, C., Kiliku, P., Mapunda, G., Muhdhar, R., Mtana, N., Tarimo, E. Ankomah, Y.,Forde, L. D, Osei-Amankwah, L., Afitska, O., Clegg, J. (2010) Language of Instructionand Quality of Learning in Tanzania and Ghana. EdQual Policy Brief No 2, $09 / 10$ p. 1.

[16]. Sackey, J.A (Ed.) (2007) “The English Language in Ghana: A Historical Perspective,” inEnglish in Ghana, M.E. Kropp Dakubu. Accra: Ghana English studies Association.

[17]. Scott B. (2011) Why the education industry needs readability formulas.ReadabilityFormulas.com

[18]. Sey, K. A. (1973) Ghanaian English: An Exploratory Survey. London: Macmillan

[19]. Taylor, W. (1956). Recent Developments in the use of "Cloze Procedure." Journalism Quarterly,33, (1), 42 -48, 99.

[20]. Wellington, J. \& Osborne, J. (2001). Language and literacy and science education. Buckingham,England: Open University Press.

[21]. Wireko, V. (2009). Ghana last in Science and Maths? How come? Daily Graphic, Reality Zone,8/09

[22]. Yong, B. C. S. (2003). Language problems in the learning of biology through the medium ofEnglish, Journal of Applied Research in Education, 7(1), 97-104

[23]. Yong, B. C. S. (2010) Can Students Read Secondary Science Textbook Comfortably? BruneiInt. J of Sci. \& Math. Edu., Vol. 2(1), 59-67.

\section{Beginning}

\section{Appendix A Passages Selected From Physics Textbook}

Sound energy passing a point per unit area perpendicular to the direction of the wave is the intensity of the wave. The intensity of a wave is proportional to the square of the amplitude of the wave. Loudness is proportional to the intensity but not equal to it. Loudness depends on the sounds produced around and on the listener's own aural awareness. Sounds which in some circumstances may stand out as loud may not even be heard under other circumstances. As an example the sound of a cutlass cutting wood in a farm in the forest may be loud enough to be heard from afar. The same cutting of wood in the timber market may not attract any notice.

Loudness is therefore measured as comparative intensity, the ear responding to intensity in what appears to be an exponential relationship. The unit of measurement is the bel, which is rather a large unit. The unit in practical use is the decibel, one tenth of the bel. Generally, the ear is more sensitive to sounds of higher frequencies. Below is a list of sounds and their rating in decibels. This rating is merely comparative, the ear responding to the ration of powers and not the difference between the powers of two sounds. The list produced by using a sound level meter to monitor sound pollution.

Middle

It is not possible these days to do many things without making use of scientific devices and principles. Transport, industrial processes, entertainments, everyday objects such as pens, electric lights, wristwatches etc all use applied science. This makes the study of science very important. By the time students leave school they should be familiar with the scientific principles, know how the mind of the scientist works, understand the world in which science has so much influence and plays such a vital role, and in which one must work. At this level in education it is necessary to go more deeply into the various branches of science for a more thorough understanding of each. The scientific knowledge available is so vast that an attempt to understand every bit of it is impossible. It is reasonable however to learn a little of some part. This may be done by studying physics and practicing the techniques used by a physicist. 


\section{Towards The End}

Taking, as an example, the parent isotope as uranium-238, it breaks down giving off radiation and causing the nuclide to change to other nuclides. The gradual decay occurs spontaneously and randomly. However, there are particular emissions at each stage. The decay may emit an alpha particle such as occurs when the nuclide has changed to polonium-210. All three forms of radiation were discovered in radium which is a mixture of radium and the products of its decay. Their nature was not known at at first and so they were named alpha, beta and gamma rays. All the alpha particles are emitted with the same velocity whereas the beta particles have different velocities. They are readily absorbed by air, paper and even by the surface of the skin of the body. The beta particles, high kinetic energy electrons, have varying energies and ranges in air and are absorbed by thin metal such as tin foil. The most penetrating is the gamma ray emission and can effectively be absorbed by thick lead or concrete; the beta particle can penetrate about ten times the distance penetrated by the alpha particle in air. The alpha particle causes greater ionisation of the air than does the beta particle. Gamma rays also cause ionisation of air particles.

\section{Beginning}

\section{Passeges Selected From Integrated Science Textbook}

The work of the scientist is far-reaching in every aspect of life. A lot of information about science can be found through the media (radio, TV and newspapers), and by reading scientific journals, magazines and books. These sources will show you how science has been involved in aspects of everyday life around you. For example, deciding which metals should be used to build suspension bridges such as the Adomi Bridge at Atimpoku or Beposo; a scientific knowledge of how drugs work will help to improve their use and avoid their abuse; scientific knowledge has led to the extraction of gold, aluminium, silver and precious metals. Science is involved from soap and perfume manufacture to the development of complex electronics and rocket technology, and cures for malaria, cancer and other diseases. Technology can be described as all the knowledge and scientific skills available to society being applied to improve life and to satisfy the need of people. There is a close relationship between technology and science in particular, and with other disciplines. For example, historical accounts and awareness of the use of tallow, animal fat from goats, sheep or cattle, gives important information to soap chemists on one material in soap production. It leads to a search for other fats and oils of the same or similar chemical structure, that can be used for the same purpose to give better quality and yield of soap.

\section{Middle}

Mining of Gold, diamonds, bauxite and other minerals has grown annually and export earnings have been encouraging. However, mineral exploitation has caused irreparable damage tot he environment in certain places. The necessary precautions must be taken to minimise or avoid this kind of damage. Growth in the agricultural sector has been too low to off-set the population growth rate of around 3.0 per cent. There has always been importation of cereals and meat to meet additional requirements. Some of the causes of inadequate agricultural production are: misuse of agro-chemicals and poor agricultural techniques, a fast-growing population whose immediate needs, land and food, take precedence over long-term national policies and strategies for sustainable development, increasing demand for agricultural land, per capita agricultural land which was estimated at 1.95 ha around 1990 is expected to fall to 0.43 ha by the year 2020 . The high demand has forced poor farmers to farm marginal lands such as steep slopes and fragile soils, mechanisation and the uncontrolled use of agrochemicals in the modern agricultural sector have created serious environmental problems. For example, the destruction of the natural balance of soil components, the problem of desertatification continues to assume serious dimensions in the Upper East and Upper West Regions.

\section{Towards The End}

The internet is a worldwide system of computer networks in which a user at one computer can get information from any other computer (and sometimes talk directly to users at other computers). It was originally developed in 1969 by the US government's Advanced Research Projects Agancy. the original aim was to create a network that would allow users of a research computer at one university to be able to 'talk' to researcher computers at other universities. Thirty years on, the Internet has become a public cooperative, and self-sustaining facility. It can be accessed by hundreds of millions of people worldwide, using existing public telecommunication networks, for the cost of a local telephone call. E-mail (electronic mail) is the exchange of computer-stored messages by telecommunication over the internet. For many Internet users e-mail has practically replaced the postal service for short written transactions. It is the most widely used application on the Internet. E-mail messages are usually encoded in plain text, but you can also send non-text files, such as graphic images and sound files, as e-mail attachments. E-mail can be distributed to lists of people as well as to individuals. Some mailing lists allow you to subscribe by sending a request to the mailing list administrator. A 
mailing list that is administered automatically is called a list server. You can also carry on live 'conversations' with other computer users, using internet relay chat (IRC).

\section{Passages Selected From Chemistry Textbook \\ Beginning}

Chemistry forms the roots of the chemical industry. The aim of this industry, since the time of our early ancestors, has been to better the standard of living by improving on the natural resources of the world. Quality of clothes has improved and continues to do so. This is partly due to the development of new materials such s polyester and nylon; it is also partly due to the development of dye-stuffs and detergents. Plastics that find many uses are now becoming cheaper because of the increase in demand and supply. Some successes have been made by chemists in an attempt to discover other kinds of fuel to replace petrol, kerosene, firewood, charcoal and others. These traditional fuels are becoming scarce and costly to use. The chemical industry helps in food production by producing fertilizers, selective weed-killers and pesticides. For health, a whole range of drugs have been produced. Some of these drugs help in fighting against malaria and disease-causing bacteria. Efforts are being made today to produce fertilizers, selective weed-killers and pesticides. For health, a whole range of drugs have been produced. Some of these drugs help in fighting against malaria and disease-causing bacteria. Efforts are being made today to produce chemicals which avoid any damage or pollution to the environment. Chemists are also trying to find ways to prevent shortages of any natural resources that are important to the chemical industry.

\section{Middle}

Aliphatic compounds are compounds with carbon atoms arranged in open chains. These can be straight or branched, can contain single, double, or triple carbon-carbon bonds, or be attached to other atoms. Alicyclic compounds are those containing closed rings of carbon atoms, with the bonding electrons of the carbon atoms localized between those atoms. The names of such compounds are often prefixed by -cyclo-. Heterocyclic compounds are those which contain rings of atoms which include atoms other than carbon. Often the rings contain atoms of oxygen, nitrogen, or sulphur. Many cyclic compounds are found as natural products. They can also be synthesized. Many are used as drugs. It is important and useful for organic chemists to study our local herbs and plants in order to extract the active compounds from them. When the structure and chemical properties of the local drug are known, chemists can synthesize the compounds for wider use. Such a task is the work of scientists at the Centre for Scientific Research into Plant Medicine at Akwapim Mampong in Ghana. For example, the drug cocaine is extracted from the leaves of the coca plant (not cocoa). It used to be used as a local anaesthetic, but is now misused as a stimulant. Its effects are very dangerous to humans and it is becoming a threat to civilisation.

\section{Towards The End}

Glucose occurs naturally in ripe fruits e.g grapes, pineapples, mangoes, oranges, and other fruits, in honey and in blood. It is the product of photosynthesis in plants. In the pure form, it is a white crystalline solid, $\mathrm{mp} 419 \mathrm{~K}(146 \mathrm{C})$, with a sweet taste. It is very soluble in water through extensive hydrogen bond association, but insoluble in organic solvents such as ether and ethanol. Glucose is used widely in the food industry in production of fruit drinks and confectionery. When given in liquid form, it is useful for sick people in convalescence and sportsmen who need instant energy. Glucose has the advantage that it is easily soluble and absorbed rapidly into the blood stream. Fructose is also naturally found in ripe fruits and honey. It is a crystalline solid (mp 376-377K (103-104C)) and more soluble in water than glucose. It is estimated to be twice as sweet as glucose. It is used in making sweets and as a sweetening agent. There are carbohydrates made up of 2 monosaccharide units. An example is sucrose, commonly used as table sugar. The structure of sucrose is shown in Fig 30.5. Structurally, it is formed by condensation of a fructose and glucose molecules with the loss of one water molecule. Sucrose is the commonest of the carbohydrates that is used as food. The main source is sugar cane which is grown in many parts of Ghana on a small scale. Sucrose is produced from sugar cane of which it is about $1.5 \%$ by mass.

\section{Passages Selected From Biology Textbook}

The question of the cause of malaria remained unanswered for many years until some Algerian scientists started to think that micro-organisms might be the cause. They may have though about the problem as follows: 'Malaria may be caused by micro-organism. If this is the case, then the micro-organisms should be found inside a person suffering from malaria.' They looked for micro-organisms inside the bodies of malaria patients and observed that their blood contained a type of protoctist called Plasmodium in large numbers. As a result of this observation, the scientists suggested the hypothesis that Plasmodium was the cause of malaria. More scientists agreed with this hypothesis. Before they could test it, however, they had to find out how 
Plasmodium entered the blood. They knew, from the observations of ancient people, that the disease was associated with marshy places, but that marsh water was not the cause. Therefore it must be something else which is found in, or near, marshy places. A further observation was necessary to determine this thing. This observation revealed that mosquitoes were found in marshy places. it was also noticed that when a marsh dried up, the population of mosquitoes was reduced and the number of people getting malaria decreased. This led people to suspect that mosquitoes transferred Plasmodium from a malaria-diseased person to a healthy person when they bit them.

\section{Middle}

Human population growth through development of medical services has resulted in the use of vast areas of land and consequently its pollution. Gathering food has developed from primitive collection of wild fruits and hunting with stone age implements through to mechanised farming. The use of the axe had little effect on the dense forest of the central belt of Ghana: the hoe and the cutlass could only scratch a little top soil out at a time. However, technological development has brought about chainsaws, bulldozers and dynamite. These can cause a lot of damage to the soil. The traditional gold mining locally called 'galamsay', through sophisticated mining techniques, has assaulted the land resources and the naturally beautiful scenes, and replaced them with heaps of debris and waste. Some of these waste contain toxic and corrosive chemicals that pollute the soil. Stone quarries are increasing in number and growing into large commercial ventures, increasing the disfiguring of the landscape. Who fills the gorges created? When will the devastated forest grow again to provide shelter for the game and wildlife? Will it ever be possible to reclaim the sites? Settlements are growing from dotted family huts into estate housing, from community houses into mighty mansions and, in some countries, skyscrapers. Soon Nsawam and Aburi may be suburbs of Accra, and Kumawu a street in Kumasi.

\section{Towards The End}

A number of theories have been proposed in an attempt to explain the reason for the infinite variety of life on this planet. The two main arguments put forward are those of special creation and evolution. Supporters of special creation believe that all living organisms were created by a divine being or God. Some believe it coincided with the creation of the Earth. Others believe it to have happened several times throughout the history of the world. Creationists assume that living things have remained unchanged throughout history and are exactly as they were when they were first created. Since this creation occurred at the beginning and cannot be observed, this places the theory outside the framework of scientific investigation. Evolutionary theories argue that the huge variety of organisms present today have slowly developed, or evolved, over millions of years from a few simple life forms. Lamarck's theory involves the inheritance of acquired characters. The theory is resolved into three components: influence of the environment, use and disuse of body parts and inheritance of acquired characters. Individuals of the same species growing and developing under different environmental conditions differ from one another (e.g plants in shade develop larger leaves than those in the open where light intensity is higher). Etiolation (weak, long stems with no chlorophll) occurs in plants grown in darkness.

\section{CLOZE TEST PHYSICS}

\section{Appendix B}

In the following passage some of the words have been left out. First read over the whole passage and try to understand what it is about. Then try to fill in the spaces. It takes only one word to fill in each space. You may use the words in table P1 at the bottom of the page to help you. Try to fill all the spaces.

Here is an example showing how to fill a space:

I would like .......... be a Scientist.

I would like ............ be a Scientist.

to

Sound energy passing point per unit perpendicular to the of the

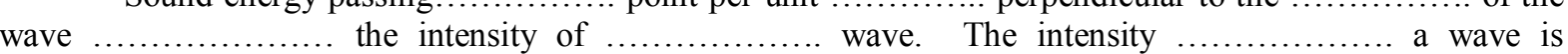

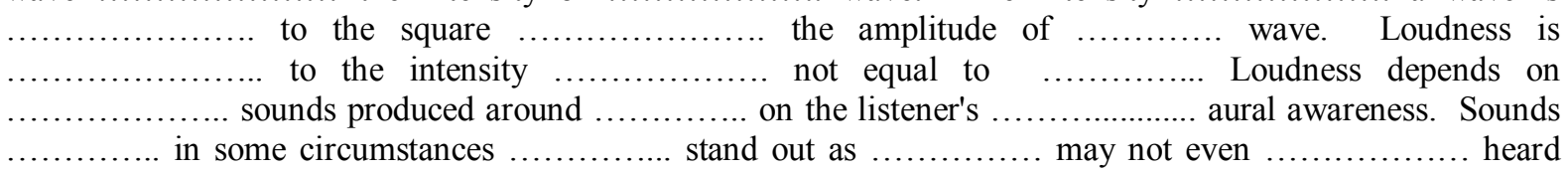

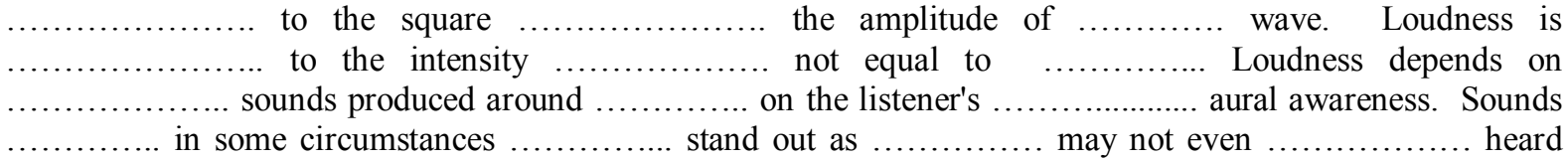

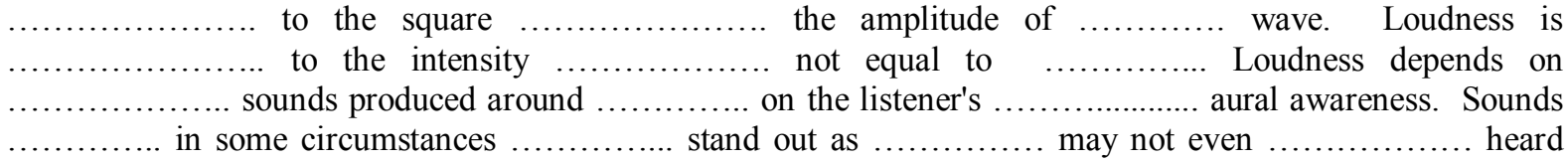
under other ............... As an example .............. sound of a .................. cutting wood in

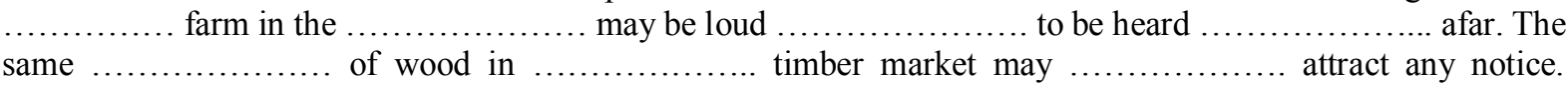
is therefore measured............... comparative intensity, the responding to intensity ............... what appears to ............ an exponential relationship. unit of measurement the bel, which rather a large The unit in use is the 
one tenth of bel. Generally, the is more sensitive sounds of higher .................. Below is a .............. of sounds and rating in decibels. rating is merely ................, the ear responding .. the ration of

Table 1

\begin{tabular}{|l|l|l|l|l|l|l|l|}
\hline cutlass & be & The & to & the & of & proportional & of \\
\hline enough & from & cutting & the & not & Loudness & as & in \\
\hline the & ear & Is & frequencies & list & their & This & powers \\
\hline the & proportional & but & it & the & and & own & which \\
\hline may & loud & be & circumstances & the & a & a & forest \\
\hline area & direction & unit & ear & is & is & practical & decibel \\
\hline comparative & to & & & & & & \\
\hline
\end{tabular}

\section{CLOZE TEST}

\section{INTEGRATED SCIENCE}

In the following passage some of the words have been left out. First read over the whole passage and try to understand what it is about. Then try to fill in the spaces. It takes only one word to fill in each space. You may use the words in table 1 at the bottom of the page to help you. Try to fill all the spaces.

Here is an example showing how to fill a space:

I would like ......... be a Scientist.

I would like .......... be a Scientist.

\section{INTEGRATED SCIENCE}

The work of $\ldots \ldots \ldots \ldots$..... scientist is far-reaching .......... every aspect of .......... A lot of $\ldots \ldots \ldots \ldots \ldots . . .$. about science can ........... found through the ............ (radio, TV and ............), and by reading ............ journals, magazines and .......... These sources will ............. you how science .. been involved in ............ of everyday life .......... you. For example, ............. which metals should ........... used to build ........... bridges such as ........... Adomi Bridge at ........... or Beposo; a ........... knowledge of how ......... work will help ............. improve their use ............. avoid their abuse; ............ knowledge has led ............. the extraction of ............., aluminium, silver and ........ metals. Science is ............ from soap and ............... manufacture to the ............ of complex electronics ............. rocket technology, and ......... for malaria, cancer ............ other diseases. Technology ............ be described as $\ldots \ldots \ldots \ldots \ldots$ the knowledge and ............. skills available to ............... being applied to ............... life and to ............. the need of There is a relationship between technology science in particular, ............... with other disciplines. example, historical accounts ............... awareness of the .............. of tallow, animal ............. from goats, sheep ................. cattle, gives important to soap chemists one material in

\section{Table 1}

\begin{tabular}{|l|l|l|l|l|l|l|l|}
\hline scientific & development & society & all & and & perfume & cures & involved \\
\hline scientific & gold & fat & information & use & has & precious & to \\
\hline satisfy & newspapers & and & close & or & improve & can & on \\
\hline drugs & scientific & people. & For & and & around & and & and \\
\hline information & Atimpoku & deciding & soap & and & books. & be & aspects \\
\hline scientific & suspension & in & show & to & be & life & media \\
\hline the & the & & & & & & \\
\hline
\end{tabular}

\section{CLOZE TEST}

\section{CHEMISTRY}

In the following passage some of the words have been left out. First read over the whole passage and try to understand what it is about. Then try to fill in the spaces. It takes only one word to fill in each space. You may use the words in table 1 at the bottom of the page to help you. Try to fill all the spaces.

Here is an example showing how to fill a space:

I would like .......... be a Scientist.

I would like ........... be a Scientist.

Chemistry forms the of the chemical . The aim of .... industry, since the $\ldots \ldots \ldots \ldots \ldots \ldots$ of our early by improving on , has been to the standard of natural resources of .............. world. Quality of has 
improved and

to do so.

is partly due the development of materials such as and nylon; it also partly due

the development of ................. and detergents. Plastics and detergents.

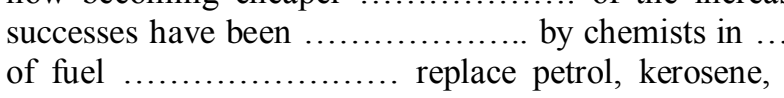

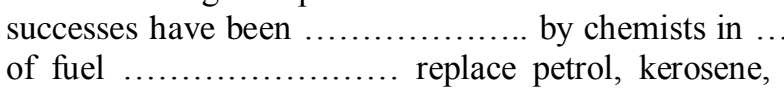
traditional fuels are ................. scarce and costly in food .............. by producing fertilizers, health, a whole .............. of drugs have against malaria and d................... $\ldots \ldots \ldots \ldots \ldots \ldots$ fertilizers, selective weed-killers
range of $\ldots \ldots \ldots \ldots \ldots \ldots \ldots$ have been produced. against and disease-causing bacteria. 